\title{
A Multi-Model Pipeline for Translational Intracerebral Haemorrhage Research
}

\author{
Sarah E. Withers ${ }^{1}$ - Adrian R. Parry-Jones ${ }^{2,3}$ - Stuart M. Allan ${ }^{1}$ • Paul R. Kasher ${ }^{1}$ (I) \\ Received: 15 May 2020 / Revised: 18 June 2020 / Accepted: 23 June 2020 / Published online: 7 July 2020 \\ (C) The Author(s) 2020
}

\begin{abstract}
Apart from acute and chronic blood pressure lowering, we have no specific medications to prevent intracerebral haemorrhage (ICH) or improve outcomes once bleeding has occurred. One reason for this may be related to particular limitations associated with the current pre-clinical models of ICH, leading to a failure to translate into the clinic. It would seem that a breakdown in the 'drug development pipeline' currently exists for translational ICH research which needs to be urgently addressed. Here, we review the most commonly used pre-clinical models of ICH and discuss their advantages and disadvantages in the context of translational studies. We propose that to increase our chances of successfully identifying new therapeutics for ICH, a bidirectional, 2- or 3-pronged approach using more than one model species/system could be useful for confirming key preclinical observations. Furthermore, we highlight that post-mortem/ex-vivo ICH patient material is a precious and underused resource which could play an essential role in the verification of experimental results prior to consideration for further clinical investigation. Embracing multidisciplinary collaboration between pre-clinical and clinical ICH research groups will be essential to ensure the success of this type of approach in the future.
\end{abstract}

Keywords Pre-clinical $\cdot$ Intracerebral haemorrhage $\cdot$ Disease models $\cdot$ Drug discovery

\section{Introduction}

Stroke is the second highest cause of death worldwide, surpassed only by ischaemic heart disease [1]. The most devastating sub-type of stroke, intracerebral haemorrhage (ICH), accounts for 10-20\% of all strokes in high-income countries, whilst incidences increase in central and East Asia and subSaharan Africa [2]. ICH has a mortality rate of $40 \%$ at 1month post-ictus, coupled with a higher loss of disability

Paul R. Kasher

paul.kasher@manchester.ac.uk

1 Division of Neuroscience and Experimental Psychology, School of Biological Sciences, Faculty of Biology, Medicine and Health, Manchester Academic Health Science Centre, The University of Manchester, Oxford Road, Manchester M13 9PT, UK

2 Division of Cardiovascular Sciences, School of Medical Sciences, Faculty of Biology, Medicine and Health, Manchester Academic Health Science Centre, The University of Manchester, Oxford Road, Manchester M13 9PT, UK

3 Manchester Centre for Clinical Neurosciences, Salford Royal NHS Foundation Trust, Manchester Academic Health Science Centre, Stott Lane, Salford M6 8HD, UK adjusted life years, exceeding that of ischaemic stroke despite lower prevalence $[1,3]$. Knowledge of the molecular pathophysiology surrounding haemorrhagic stroke has vastly increased in recent years, with a plethora of reviews describing the primary and secondary injury phases [4-9]. Key modifiable risk factors for ICH are well recognised, and addressing these can reduce incidence [3, 10-14]. There is still, however, a complete lack of specific treatments available to improve outcomes following $\mathrm{ICH}$, despite many drugs showing efficacy in preclinical models [18]. Therefore, ICH treatment is focussed on quick diagnosis followed by reversal of anticoagulants, blood pressure management and surgery in carefully selected patients as determined by guidelines for the management of spontaneous ICH [15-18]. One reason for the current lack of specific treatments in $\mathrm{ICH}$ may be due, in part, to specific limitations associated with the most commonly used existing pre-clinical models of the disease, including constraints related to generating spontaneous brain haemorrhages, difficulties in observing brain pathologies in live animals and sub-optimal experimental study design [19]. It would seem, therefore, that a breakdown in the current 'drug development pipeline' exists for ICH. As such, there is an urgent requirement to rethink our strategies for translational ICH research so that we can investigate new therapeutic avenues for 
future patient treatments, as highlighted in the Haemorrhagic Stroke Academia Industry (HEADS) initiative [20]. This review reinforces some of the priorities raised by HEADS, and how these may be implemented within preclinical ICH research, with our main focus highlighting the need for a more efficient, multidirectional pipeline. A more strategic approach to ensure the most appropriate models/systems are selected for each phase of the pre-clinical pipeline (such as studying the occurrence of bleed/risk factors, injury responses or treatments) would be beneficial (Fig. 1). To aid with this decision, the current pre-clinical ICH models will be discussed, including their advantages, disadvantages (see Table 1) and how translational $\mathrm{ICH}$ research may be potentially strengthened by adopting multiple models in parallel and embracing multidisciplinary collaboration.

\section{In Vitro Models}

In vitro studies dominate the start of the pre-clinical pipeline, where they are commonly used to complement the work from in vivo studies, especially when a pharmacological agent is being tested in rodents. The in vitro work can provide vital information on the mechanism of action, and the effects of the compound on a particular cell type, thus demonstrating the advantages of drug screening in vitro [21-28]. Typically, primary cortical neurons, microglia, astrocyte, mixed glia cultures or endothelial cell cultures are used to emulate the effects of blood on various brain specific cells that are affected following ICH. This can be beneficial for characterising the subsequent response to blood molecules in individual cell types, but less useful for identifying interactions between different brain resident cells. Further advantages of using cell-based systems include the relative ease of genetic manipulation, by using siRNA, gene editing, adenoviruses or plasmid transfections to knock down or over-express various anti- or proinflammatory genes or receptors, thus enabling further characterisation of the neuroinflammatory response in a relatively small time period [23, 25-27, 29].

The most conventional approach to producing an in vitro model of ICH is by stimulating the cells with a blood component to mimic the effects of intraparenchymal haemorrhage on brain resident cell types. The serine protease thrombin is activated during coagulation, and has been used to stimulate microglial cultures to determine their response to transforming growth factor $\beta 1$ (TGF- $\beta 1$ ) [30]. Oxyhaemoglobin (oxyHb) and haemoglobin $(\mathrm{Hb})$ have been used to increase understanding of less common cell death mechanisms, such as necroptosis and ferroptosis [23, 24]. Furthermore, whole blood from donor mice has been used with the aid of a porous membrane insert to stimulate primary cortical neurons to allow observation of the full haemotoxic response, specifically erythrocyte lysis and haemoglobin release [31]. However, the most widely used method utilises haemin, the oxidised form of haem, which upon erythrocyte lysis is released from haemoglobin and has been shown to contribute to secondary brain injury following ICH [21, 22, 24-29, 32-34].

One challenge associated with these in vitro models is maintaining relevance to the complexity of the human condition. Following ICH, brain tissue is exposed to approximately $10 \mathrm{mM}$ of haemin, whilst the concentrations used in vitro rarely exceeds $100-\mu \mathrm{M}$ haemin [29]. Furthermore, individual cell types can exhibit differences in their sensitivity to haemin. This may potentially confound downstream analyses, but could also provide interesting insight into specific functions

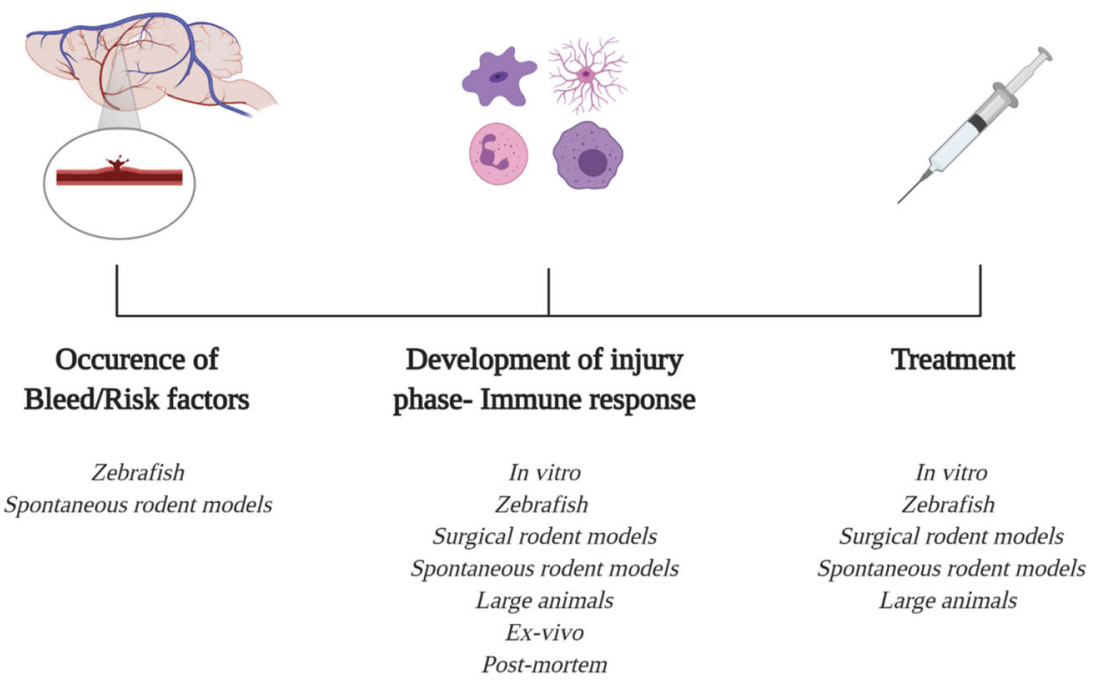

Fig. 1 ICH timeline. This timeline represents the major factors which can be studied in pre-clinical ICH models/systems. Mechanisms that underpin ICH risk can be explored in spontaneous ICH models, such as hypertensive rodents and zebrafish models. Secondary injury progression can be readily observed in all the pre-clinical models, and observations can also be verified in patient tissue such as serum and post-mortem brains. Lastly, potential treatments can be tested across all pre-clinical animal and cell models, where novel candidate therapeutics could be identified through high-throughput screens (e.g. in vitro, zebrafish) and subsequently verified in a mammalian system 


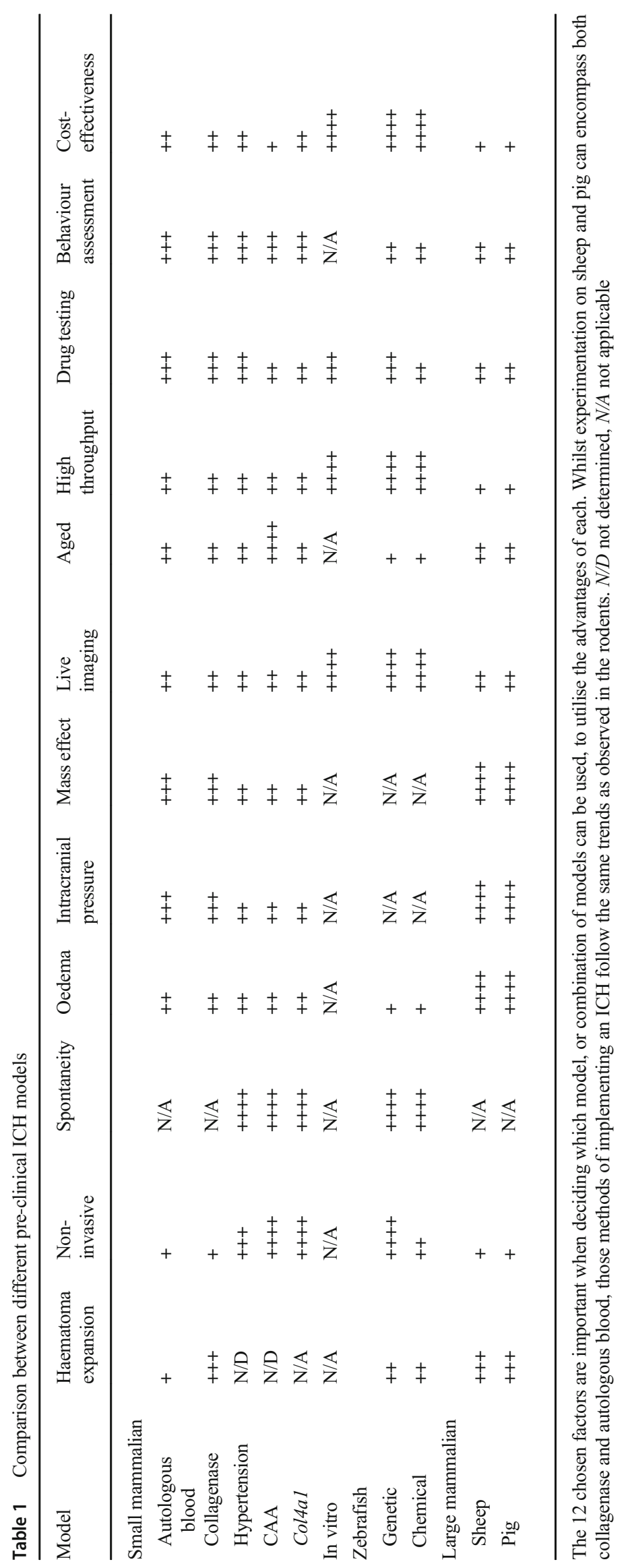


of particular cell types. For example, microglia are less vulnerable to haemin due to their ability to upregulate inducible nitric oxide synthase and haem oxygenase-1 [33]. Goldstein and colleagues hypothesised that in an intact central nervous system (CNS), the toxicity propagated by haemin could be dampened by endogenous antioxidants or other compounds which are not present in these specific cultures, thereby alluding to why such low concentrations of haemin has to be used experimentally [34]. Moreover, only stimulating cells with one blood component do not allow for the full effects of haemotoxicity to be observed, and the time course by which the brain resident cells become affected. Ultimately, simple cell models cannot accurately portray the haematoma expansion or many of the complex mechanisms of primary and secondary injury, hence why they are so often performed alongside in vivo rodent studies.

\section{Small Mammalian Models}

The most widely used animals for experimental ICH research are rodents. Although rabbit models also exist, they are predominantly used for subarachnoid haemorrhage research, and as such, will not be discussed here [35-38]. A PubMed assessment of the literature using the search terms 'intracerebral haemorrhage in rats' and 'intracerebral haemorrhage in mice' identified 497 studies published since 2015. These studies could further be divided into two categories: those characterising the pathophysiology of ICH $(n=303)$; and those evaluating candidate therapies $(n=194)$. Despite a large number of the latter reporting beneficial effects, none of the treatments have as yet translated successfully to the clinic. Based on these observations, it would appear therefore that the current translational pipeline is not working. The vast majority of rodent ICH models are non-spontaneous and involve invasive techniques to generate a bleed, through stereotaxic injection of autologous blood or collagenase, and thus do not precisely mimic the human disease, as described below.

\section{Autologous Blood Injection Model}

The autologous blood injection model was developed as a controllable and reproducible animal model of ICH, and has undergone many cycles of optimisation since its introduction in 1984. Previously, Ropper et al. had used arterial blood from a donor rat injected into the right caudate nucleus of a recipient rat in order to observe differences in regional blood flow [39]. The use of donor blood quickly became obsolete, leading to the advent of autologous blood taken from the femoral artery before injection into the caudate nucleus [40]. Currently, the most successful model involves a stereotactic injection of autologous blood at two stages into the caudate nucleus. This double injection, first implemented in 1996, was used to allow a small amount of blood to clot, in order to prevent backflow along the needle track, enabling the remaining volume of blood to emulate the haematoma [41]. Following its success in rats, the model has also been implemented for use in mice, where similar effects have been elicited [42-44].

This model is useful at recapitulating a single bleed, which is easily reproducible, and mimics many of the key traits observed in the human condition, such as mass effect, brain oedema, neurological deficits and neuroinflammation $[42$, $43,45,46]$. The neuroinflammatory response includes innate immune cell infiltration, activation of brain resident immune cells, oxidative DNA damage and pro-inflammatory cytokine release, all of which have been identified as potential therapeutic targets [43]. However, the autologous blood model lacks the spontaneous nature of haemorrhage, and cannot be used to research haematoma expansion, which is present in $1 /$ 3 of patients during the first 24-h post-ictus [7]. Therefore, the primary use of the autologous blood model is to investigate the direct effects of haemotoxicity on the brain.

\section{Collagenase Injection}

The collagenase model is the most commonly employed technique for inducing ICH in rodents. This involves the injection of collagenase, a metalloproteinase that degrades interstitial and basement membrane collagen, into the brain via stereotactic injection [47]. Collagenase causes disruption of the basal lamina of the desired cerebral arteries, resulting in blood leaking through the vessels, first achieved in rats by Rosenberg and colleagues in 1990 [47]. Bleeding was observed from 10-min post-injection, with the haematoma volume correlating to the concentration of collagenase used. Various alterations to this model can be made depending on the research question. For example, different brain locations can be injected, although the most commonly used is the right basal ganglia, which reflects the high proportion (35-70\%) of patients who develop a 'deep' bleed [48, 49].

As with the autologous blood injection, there are caveats associated with the collagenase model, primarily revolving around the potential neuroinflammatory properties of the enzyme [50, 51]. However, in vitro studies have demonstrated that collagenase alone does not activate microglia, alter prostaglandin E2 production or induce apoptosis [51, 52]. Furthermore, in comparison to the autologous blood model, there is not an increased neuro-immune response attributed to collagenase, as both models display comparable temporal patterns of inflammation $[52,53]$. Another disadvantage with the collagenase model is the difficulty in obtaining a relevant sham. Current practice uses a sham model where saline is injected into the brain [54]. However, one could argue that a better sham would be through injection of inactivated collagenase into the brain, thus controlling for potential collagenase-induced inflammation. 
Comparative studies between the autologous blood and collagenase model have several key findings. The collagenase injection produces a greater primary injury, most likely attributed to the haematoma expansion which can occur in this model. Interestingly, despite autologous blood generating a more concentrated blood volume and greater initial mass effect, the collagenase model still induces more cell death, oedema and inflammation $[45,55]$. There is conflicting literature regarding neurological impairment, which is suggested to be more sustained in the collagenase model, thus rendering it advantageous when observation of long-term deficits of ICH is desirable [45]. Contrastingly, another group saw more long -term motor impairments in the autologous blood model [55]. Ultimately, choice of model depends on the research question being asked. However, the translational relevance of these models has been called into question, thus reiterating the need to develop less invasive and more spontaneous techniques, or coupling these models with other experimental methods in an attempt to more closely recapitulate human ICH [20].

\section{Spontaneous Haemorrhage Models}

Although less common, there are rodent models that haemorrhage spontaneously, thus negating the need for surgery, and potentially mimicking the clinical risk factors of ICH more closely. As such, these may be considered as more translationally relevant pre-clinical models, although the location of the bleed and haematoma size cannot be controlled and are often inconsistent between animals, as opposed to the surgically induced ICH models. The main models discussed in this section represent major risk factors for ICH in patients: hypertension, cerebral amyloid angiopathy (CAA) and cerebral small vessel disease (CSVD). The HEADS committee also highlighted the need to develop models of modifiable and non-modifiable risk factors, such as alcoholism and ageing to further understand how ICH can be prevented in these populations, as there are relatively few papers which utilise these risk factors [20, 56-63].

\section{Hypertension}

In the 1970s, Okamoto and Aoki generated the spontaneously hypertensive stroke prone (SHRSP) rat model, associated with cerebral lesions that encompassed a wide range of microinfarcts, petechial haemorrhages and larger haemorrhages in locations such as the cerebellum [64, 65]. Furthermore, after the addition of a high salt diet or inhibitor of nitric oxide synthase N $\omega$-nitro-L-arginine methyl ester hydrochloride (LNAME), the SHRSP rats exhibited larger haemorrhagic events, which were coupled with ischaemia in the L-NAME-treated animals $[66,67]$. Ahmad found that after L-NAME treatment, angiotensin receptor antagonist delayed the onset of stroke, thus identifying a potential pathway which may be implemented in hypertension-induced stroke [67].

Following on from the SHRSP rats, Lida and colleagues were the first group to engineer a model of spontaneous ICH in hypertensive mice, where the location of the bleeds identified were similar to those found clinically, such as the brain stem, cerebellum and basal ganglia [65]. Chronic hypertension was achieved by creating a double mutant, overexpressing the human renin and angiotensinogen genes. The mutants were also fed a high salt diet, coupled with L-NAME. A caveat with this study was the survival rates of these mice, which all died within 10 weeks, thereby preventing the ability to observe full recovery following ICH.

The same group then modelled hypertension using a nontransgenic approach by adding L-NAME to the drinking water to induce chronic baseline hypertension, followed by infusion of angiotensin II or norepinephrine to generate an acute hypertensive spike, which was successful at inducing ICH in similar clinical locations to their previous study $[65,68]$. This spontaneous model has been valuable in increasing the mechanistic understanding of hypertensive $\mathrm{ICH}$, with particular focus on the role of superoxide and lysyl hydroxylase 3 , and how targeting these may act as an intervention to prevent ICH in hypertensive populations $[69,70]$. Furthermore, RNAseq analysis from the cerebral vessels of this hypertensive mouse model identified potential key biomarkers for hypertension-induced ICH, including cancer-related pathways, mitochondrion and MHC II proteins, which may help with ICH diagnosis, although these observations need to be confirmed in hypertensive ICH patients [71].

\section{CAA}

Rodent models of CAA differ predominantly in the mutated region of the amyloid precursor protein (APP) gene, but they all develop amyloid deposits that bind to the blood vessels and disrupt neurovascular integrity. CAA is a large risk factor for ICH patients above 70 years old; therefore, to mimic the clinical scenario, older animals are utilised in these studies. [14, 20].Winkler et al. were the first group to show that mutations in APP23 mice overexpressing $\mathrm{APP}_{751}$ with the Swedish double mutation (K670N/M671L) under the control of a neuronspecific-Thy-1 promoter, exhibited evidence of brain haemorrhage in 27-month old mice [72]. The haemorrhage sites correlated with the CAA vessels, providing rationale for CAA being the driving force behind vessel rupture and bleeds in these transgenic mice. Similarly, a Dutch mutation mouse (E693Q) was generated in the same way, also using $\mathrm{APP}_{751}$. These mice exhibited haemorrhages at 29 months, although the location and frequency of bleeds were not described [73]. Following on from this, a Swedish, Dutch and Iowa (D694N) triplemutant $\mathrm{A} \beta \mathrm{PP}_{770}$ mouse was produced, also developing microbleeds [74]. Whilst the frequency of these bleeds was 
low, this could be due to the mice being sacrificed at 12 months, and so with a longer life span, it is possible that occurrence of bleeds would have increased. Another study using the Swedish double mutation highlighted the significant increase in the number of microbleeds between 15- and 24-month old mice, further reiterating the need to prolong experimentation when using these models [75].

Some groups have explored the combination of CAA mice and hypertension, which illustrates the importance of investigating multiple risk factors for ICH together, as a patient will often present with a number of comorbidities which can work synergistically to cause a bleed. Over-expression of $\mathrm{APP}_{695}$ with the Swedish mutation replicated Alzheimer's pathology, whilst L-NAME treatment and a brief angiotensin II infusion created chronic hypertension. Subsequently, transient acute hypertension was generated by daily doses of angiotensin II. The resulting hypertensive CAA mice had an increased susceptibility to spontaneous ICH at 15 months old [76]. Whilst this is very successful at producing an all-encompassing spontaneous model, major caveats are associated with increased technical demand of generating sufficient hypertension, coupled with the prolonged study time.

\section{Col4a1}

Collagen type IV is an integral part of the basement membrane, and is pivotal in providing structural support to tissues. Mutations in the isoform COL4Al have been identified in CSVD, haemorrhagic stroke (particularly in younger individuals), familial porencephaly and aneurysm formation of the carotid artery [77]. Newborn mice with mutations in Col4a1/ a2 also exhibit haemorrhage phenotypes. Similarly, older mice experience structural defects in large calibre arteries, as observed in the descending aortae, where focal separation of the endothelium from the media altered the vascular smooth muscle and endothelial cell function. It is hypothesised this may also occur in other large calibre arteries such as the carotid, and may provide rationale for the increased likelihood of ICH in these animals [77]. Another group recreated different Cola4a1/a2 mutations in mice to understand the genetics and mechanisms that can lead to bleeding, in the hope to improve patient prognosis and treatment for the specific mutations [78]. They also identified several modifiable risk factors which may increase the risk of developing an ICH in this population, such as anticoagulant treatment, acute exercise and vaginal delivery at birth, although these factors would need to be considered on an individual basis, rather than a blanket statement for all COL4A1 patients [78]. Recently, a Col4al mutant mouse model has been used to mimic deep spontaneous haemorrhages which can occur in patients [79]. A novel segment (transitional segment) was identified between arterioles and capillaries which was hypermuscularised in the mutant mice, thought to play a role in the development of ICH due to subsequent increased intravascular pressure in the upstream feeding arteriole. This study also utilised postmortem (PM) brain tissue from deep ICH fatalities to corroborate the mouse data. Therefore, this study is a prime example of how using different systems (i.e., mouse models + PM material) can increase confidence in the translational relevance of pre-clinical discoveries.

Despite poor clinical translation in terms of new treatments, the usefulness of both surgical and spontaneous ICH models cannot be disputed, as they have proven vital in studying the multi-faceted effects of ICH within a whole organism. Rodent ICH models have provided the ability to investigate the effects of neurotoxic insults from blood, the infiltrating immune response, neurological deficits and behavioural alterations. However, with the autologous blood and collagenase model, the surgical procedures required to do this are highly invasive and have limitations on how well they truly mimic the clinical scenario. Indeed, the side effects relating to the stress associated with anaesthesia and surgery will undoubtedly confound some aspects of downstream outcome analysis. Moreover, in the past, a disadvantage of rodent models was the presence of the mammalian skull preventing observation of the pathophysiology in real time. However, now various imaging techniques can be implemented such as MRI, PET and laserspeckle. Whilst MRI is commonly used following ICHinduced surgery to view haematoma expansion and/or resolution, and laser speckle to characterise the dynamic changes in blood flow, they are not utilised in identifying bleeds in spontaneous models [55, 80-84]. This is especially apparent in the long-term studies associated with CAA, where the brain is not observed until the animal is $2-3$ years old. Prussian blue staining of hemosiderin in the brain is the sole marker used for identifying cerebral bleeds, so the timing of the vessel rupture is largely unknown [72-75]. Furthermore, spontaneous models are rarely used for drug testing, which would be useful to find preventative treatments, or to alleviate symptoms following a bleed, especially as a large proportion of ICH patients suffer from the risk factors modelled in these animals.

\section{Zebrafish Models}

Some of the limitations associated with the in vitro and rodent models can be compensated for by the emerging use of zebrafish (Danio rerio) models, which can be thought of as an intermediate between in vitro and higher order in vivo systems. Zebrafish possess many benefits as an in vivo model, such as rapid development, transparency of embryos and larvae, non-invasive in vivo imaging and ease of genetic manipulation [85]. Furthermore, as a vertebrate species, the zebrafish genome shares $\sim 70 \%$ homology with humans thus making them an advantageous system to complement mammalian models [86]. We recognise that zebrafish larvae are 
developing animals, and different disease mechanisms may exist in comparison to adult humans. However, we have shown that key characteristics associated with the pathological response to blood in the brain are apparently conserved between young fish and adult humans, suggesting they can be reliably used to model aspects of ICH $[87,88]$.

In terms of $\mathrm{ICH}$, one of the primary benefits of using zebrafish larvae is that the haemorrhage is produced in a non-invasive manner, thus arguably mimicking the spontaneous nature of human ICH more closely than the surgical rodent models. Several different genetically modified lines exist where haemorrhages are established in this way, whilst chemical induction is another common approach for inducing a brain bleed. There are 2 primary mechanisms by which a bleed can be induced: blood brain barrier (BBB) defects and weakness in the developing blood vessels. With the former, mutations in notch 3 , a regulator in brain pericyte proliferation can result in impaired BBB function and increased frequency of brain haemorrhages [89]. As such, this model may also be useful for studying aspects of CSVD.

Nascent cranial vessel weakness is induced by targeting components important in the stabilisation and development of the cerebrovasculature. $\beta$ Pix is a protein encoded for by the gene arhgef $7 b$, thought to play a role in vascular stabilisation. Mutation of $\beta$ Pix results in ICH and hydrocephalus in zebrafish larvae, thus generating the nickname 'bubblehead' for these fish/alleles [90]. Similarly, mutation of the Pak2a protein results in a different, though comparable zebrafish model of ICH, known as the 'redhead' mutant [91]. Defects in primary cilium attached to endothelial cells have been shown to disrupt cerebral-vascular integrity, resulting in ICH in the intraflagellar transport mutant [92].

Aside from genetic alterations to evoke weakness in the neurovasculature, pharmacological agents can be utilised to induce a haemorrhage in zebrafish larvae via water bath incubations and absorption. Statins are most commonly used for this and act by inhibiting the cholesterol biosynthesis rate limiting enzyme 3hydroxy-3-methylglutaryl-coA reductase (HMGCR). This leads to altered signalling via geranylgeranyl pyrophosphate (GGPP) and reduces activation of Rho GTPases, which act to regulate vascular permeability [93, 94]. Importantly, transient gene knockdown of hmgcra using a morpholino (MO) phenocopies, the haemorrhages were observed with statin treatment [94]. Targeting HMGCR not only provides a quick and reliable method of inducing ICH in zebrafish larvae, but may also afford insight into the clinical association between hypocholesterolaemia and increased ICH risk [95-99]. However, statin treatment has been shown to alter myogenesis in developing zebrafish larvae alongside reducing locomotion and heartbeat, which could potentially confound other mechanistic studies which aim to focus solely on the effects of ICH on the larvae [100].

Furthermore, there are rare genetic conditions associated with ICH which cannot be accurately represented in rodents, but can be in zebrafish. An example of this is the rare autosomal recessive interferonopathy: Aicardi-Goutières syndrome subtype 5 (AGS5). Mutations in the viral restriction factor protein SAM and HD domain containing Deoxynucleoside Triphosphate Triphosphohydrolase 1 (SAMHD1) produce an exaggerated type I interferon (IFN) response and cerebrovascular disease in some patients [101-105]. Rodent models of AGS5 exist, but these mice lack any overt physical phenotype $[106,107]$. Contrastingly, a MO knockdown of the samhd1 gene in zebrafish larvae resulted in spontaneous ICH and a significant upregulation of type I IFN [108]. Similar to AGS, another genetic autoimmune disease has been characterised in zebrafish: deficiency of Adenosine Deaminase 2 (ADA2). ADA2 encompasses systemic inflammation and a vascular phenotype arising in childhood, which can result in ischaemic or haemorrhagic cerebral events. A mouse orthologue of the gene encoding ADA2 (CECR1) does not exist; however, zebrafish express two paralogues of the CECR1 gene: cecrla and cecrlb. Following MO knockdown of cecrlb, these morphants exhibited intracranial bleeding, thus alluding to a role of ADA2 in cranial vessel development or integrity [109].

The use of zebrafish as a disease modelling tool is increasing, and as previously mentioned, they possess several key benefits for studying ICH. However, this is not to suggest that zebrafish should replace any of the well-established models, rather we propose that they should be utilised alongside other in vitro and in vivo studies. For example, using zebrafish for large-scale drug screens, and taking forward the positive hits to interrogate further in mammalian models may increase efficiency of drug development. Furthermore, this approach may also have ethical implications by reducing the numbers of mammals used for primary drug screens. Zebrafish represent a powerful model system for large drug screening studies because of their relatively high-throughput nature, and the high conservation of drug binding sites [110]. There are, however, some caveats associated with zebrafish larval models, such as the lack of skull preventing changes in intracranial pressure and mass effect to be observed following ICH. In addition, as recovery rates are so rapid in zebrafish larvae as demonstrated by Crilly et al., it poses questions on how this may differ to recovery in adult humans. However, understanding these types of processes following ICH during development may provide clues into how we might consider recovering the aged human brain in the future [87].

\section{Larger Mammalian Models}

One recurring issue with the animal models described above is their size in comparison to humans, and thus it is difficult to assure accurate translation because of obvious structural differences between rodents, zebrafish and human brains. One 
approach to address this is through the use of larger animal species, with brains more comparable to humans, in terms of size, white:grey matter ratios and the presence of gyri. The only 2 species discussed in this section are ovine and swine models; however, this is not to purposefully ignore any additional large mammalian models of ICH. The use of monkeys, canines and cats to study ICH has become largely obsolete, due mainly to ethical considerations [111, 112]. As the main premise of this review is to encourage collaborations between different ICH disciplines, it was thought best to include only those species which are widely used and more broadly accessible.

Boltze and colleagues [113] recently replicated the autologous blood model in adult sheep, observing similar histopathological observations as found in rodent models, such as brain resident cell recruitment and axonal damage. Whilst this preliminary study was used to demonstrate how ovine models can be used as a successful pre-clinical model of ICH, in the future, it is hoped that they will provide additional translational benefits when studying surgical interventions, for example like those performed in the MISTIE and STITCH trials [113-118]. Such candidate intervention techniques are infrequently implemented in other pre-clinical models, and due to the small size of brain and skull, it may be more desirable to perform these types of surgical intervention techniques in an animal model with a larger head $[37,119,120]$. Furthermore, as an aside, this was one of the few pre-clinical ICH studies to include both male and female animals, which as determined by the HEADS initiative needs to be performed more frequently across species, as it is unethical to automatically exclude half of the world's population because female experimental outcomes may differ from males [20]. The other existing pre-clinical studies experimenting on female animals have been used to mainly view hormonal differences between sexes and also how various treatment alters outcome following ICH [82, 121-125].

Swine models of both autologous blood and collagenase injection are implemented for many of the same reasons as ovine models, most notably when characterising the primary injury phase, as comparable haematoma volumes to humans can be produced, making it more beneficial to study mass effect and the mechanism of oedema formation in these larger animals [126-128]. In addition, drug treatments can also be tested in swine models, such as the iron chelator deferoxamine, where it was shown to reduce perihaematomal iron accumulation, neuronal cell death and white matter injury, comparable to its effects in a rat model of ICH [129]. However, the recent i-DEF clinical trial on deferoxamine gave rise to neutral results, thus we should utilise these larger mammalian models to optimise treatment protocols before clinical trials, such as determining the most effective way to administer a drug [130].

Surgical intervention has already been tested in a swine model, whereby following an autologous blood injection, tissue plasminogen activator (tPA) was added to lyse the clot, and the haematoma was aspirated out of the brain, resulting in a significant reduction in oedema [131]. Aside from primary injury, functional changes which occur during ICH can also be measured in the swine model, including alterations within the primary somatic evoked potentials and the resulting cortical spreading depression, which were found to be similar to what was found in a rat model previously [132].

Use of farm animals in ICH research is extremely important to understand the pathophysiology that occurs in a larger brain. However, one limitation of these models in comparison to rodents relates to a relative lack of behavioural assays currently available for measuring neurological outcomes. Furthermore, due to most pre-clinical research being directed towards rodents, it means there is a scarcity of species-specific reagents available for other models, such as sheep, pig and zebrafish, perhaps hindering the ability to look at the secondary injury response as thoroughly as can be observed in mice and rats [128]. The experimentation time is often longer than that of rodent work due to the use of older animals, leading to increased costs, and imaging capabilities are essential. The latter requires infrastructure and resources that few centres currently have.

\section{Post-Mortem/Ex Vivo Studies}

Ex vivo studies using PM brain tissue from patients who have died from ICH are surprisingly infrequent, but represent a precious and most clinically relevant source of material. Fortunately, in some instances, what is observed in human samples is comparable to findings in pre-clinical models, as seen in a small proportion of studies [79, 133, 134]. Aside from comparative studies, $\mathrm{Wu}$ and colleagues looked at the expression levels of nuclear factor-kappa B (NF-kB), macrophage inflammatory protein-2 (MIP-2) and matrix metalloproteinase-9 (MMP9) using immunohistochemistry. This was successful in enhancing understanding of the time course of brain inflammation following ICH in PM tissues [135]. Furthermore, the robust nature of PM tissue means it can be used for purposes other than just viewing the morphological and cellular characterisation of ICH brains, as demonstrated by a group who performed RNAseq analysis on the frontal and occipital lobes to understand gene expression in hereditary cerebral haemorrhage with amyloidosis-Dutch type (HCHWA-D) [136].

Whilst researching the effect of stroke on the brain is paramount, studies which utilise stroke patient blood can be extremely useful for immune profiling and 'omics-based analyses. This was recently performed by Stamova and colleagues who used RNA from both ischaemic and haemorrhagic stroke patients to reinforce the molecular differences between each condition [137]. Moreover, examining serum from ICH patients has identified the dysregulation of various pro and antiinflammatory proteins, which have also been confirmed in 
rodent ICH models [70, 138, 139]. Additionally, Taylor et al. used ICH patient plasma to determine the role of TGF- $\beta 1$ following haemorrhage. This ex vivo approach was coupled with both in vitro and in vivo experiments, demonstrating the power of using multiple models/systems, to corroborate discoveries and increase confidence in their validity [30]. Similarly, Lu et al. have recently utilised these three preclinical model systems when investigating the effects of the microRNA miR-181c following ICH [140].

There are, however, some problems with PM brain tissue, dependent on factors outside of the researchers' control, such as the availability of particular brain regions, and also the time that the brain is fixed following death $[135,141]$. The latter was shown to cause potential exaggeration of glial cell swelling, which is thought to be attributed to the fixation process in devitalised tissue, also seen in delayed fixation in rat brain [141]. Ultimately, the number of studies using PM and ex vivo tissue is minimal. Future work should focus on incorporating these valuable resources into studies, which may become more accessible if cross-discipline collaborations develop, for example, between basic scientists and brain banks.

\section{Conclusion}

In this review, we have discussed the multiple models of ICH that exist to inform about a highly disabling condition, currently with no specific medical treatment. To facilitate successful translation in the future, it is clear that there needs to be greater collaboration within the pre-clinical ICH research community to enable cross-talk between studies using different models and by utilising the advantages of each system. The most common multi-model papers exhibit experimentation on rodent and in vitro systems. Moving forward, we suggest a bi-directional 2- or 3-pronged approach for pre-clinical ICH research. For example, using the autologous blood injection rodent model, the thrombin in vitro model, and also incorporating an ex vivo element to the study, as so elegantly illustrated by both Taylor, $\mathrm{Lu}$ and colleagues recently $[30,140]$. These studies illustrate the power of using multiple systems to investigate a particular question, an approach that will hopefully become more frequently adopted for translational ICH research. Moreover, as one of the key criteria identified by the HEADS committee, we also believe it is essential for pre-clinical findings to be tested and verified in at least two different species (and not both rodents) [20]. By replicating the effect of a drug or compound identified in a smaller animal model in a higher order species such as sheep or pig, it increases the confidence that such a treatment may be efficacious in humans and worthy of consideration for clinical investigation. Furthermore, it is also apparent that the use of brain banks for PM tissue has not been utilised enough for ICH research. Human PM tissue is ideal to validate data obtained from animal models whilst also advancing our understanding of the human pathology and how it may be targeted. Therefore, the use of PM tissue should be implemented when possible, and can work in conjunction with any of the other models (see Fig. 2). Similarly, serum from ICH patients is also understudied, again reinforcing the need for increased cross-talk between pre-clinical scientists and clinicians to obtain this type of material, and to understand key differences which may be observed between comorbid populations which go on to develop an ICH and those that do not. This work would feed into the other pre-clinical work taking place, and can provide validity for the other models, if similar
Fig. 2 Multidirectional pipeline of preclinical ICH research. In this pipeline, there is both a feedforward and a feedback loop, to ensure any new findings are valid and observed across multiple models. In addition, the use of post-mortem and ex vivo tissue should feedback into all other pre-clinical models in an attempt to maintain clinical relevance. Fostering multi-discipline collaborations increases the likelihood of creating a drug which will be successful in humans, especially if it is shown to exert positive effects across the pipeline. Maximal advantages are denoted above each model/system

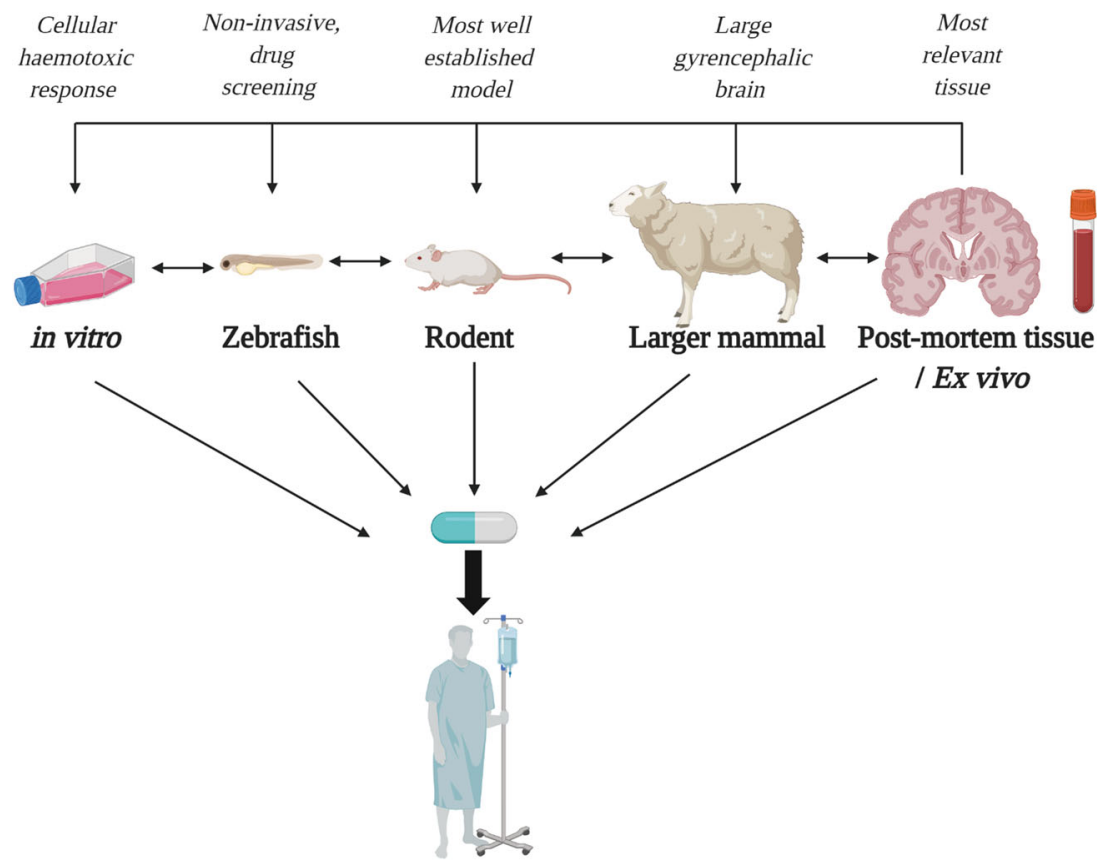


trends are observed. By fostering collaborations with different disciplines, it will strengthen the depth and breadth of ICH research, and will increase the chances of finding new treatment options for ICH patients in the future.

Acknowledgements All authors are thankful to The Natalie Kate Moss Trust for their continued financial support. The figures were created with BioRender.com.

Author Contributions Paul Kasher, Stuart Allan and Adrian Parry-Jones had the idea for the article. Sarah Withers performed the literature search and wrote the first full draft of the review with assistance from Paul Kasher. All authors critically revised the work and produced the final draft.

Funding Information This study was supported by the Medical Research Council Doctoral Training Partnership PhD Programme at the University of Manchester and an English Welsh and Scottish railway (EWS) Exceptional Contribution award to S.E.W; and the Stroke Association for P.R.K. (TSA LECT 2017/02) and A.R.P-J (SA L-RC 19\100,000).

Open Access This article is licensed under a Creative Commons Attribution 4.0 International License, which permits use, sharing, adaptation, distribution and reproduction in any medium or format, as long as you give appropriate credit to the original author(s) and the source, provide a link to the Creative Commons licence, and indicate if changes were made. The images or other third party material in this article are included in the article's Creative Commons licence, unless indicated otherwise in a credit line to the material. If material is not included in the article's Creative Commons licence and your intended use is not permitted by statutory regulation or exceeds the permitted use, you will need to obtain permission directly from the copyright holder. To view a copy of this licence, visit http://creativecommons.org/licenses/by/4.0/.

\section{References}

1. Collaborators GBDS. Global, regional, and national burden of stroke, 1990-2016: a systematic analysis for the global burden of disease study 2016. Lancet Neurol. 2019;18(5):439-58. https:// doi.org/10.1016/S1474-4422(19)30034-1.

2. Krishnamurthi RV, Feigin VL, Forouzanfar MH, Mensah GA, Connor M, Bennett DA, et al. Global and regional burden of first-ever ischaemic and haemorrhagic stroke during 1990-2010: findings from the global burden of disease study 2010. Lancet Glob Health. 2013;1(5):e259-81. https:// doi.org/10.1016/S2214-109X(13)70089-5.

3. An SJ, Kim TJ, Yoon BW. Epidemiology, risk factors, and clinical features of Intracerebral hemorrhage: an update. J Stroke. 2017;19(1):3-10. https://doi.org/10.5853/jos.2016.00864.

4. Aronowski J, Zhao X. Molecular pathophysiology of cerebral hemorrhage: secondary brain injury. Stroke. 2011;42(6):1781-6. https://doi.org/10.1161/STROKEAHA.110.596718.

5. Keep RF, Hua Y, Xi G. Intracerebral haemorrhage: mechanisms of injury and therapeutic targets. Lancet Neurol. 2012;11(8):720 31. https://doi.org/10.1016/S1474-4422(12)70104-7.

6. Ziai WC. Hematology and inflammatory signaling of intracerebral hemorrhage. Stroke. 2013;44(6 Suppl 1):S74-8. https://doi.org/ 10.1161/STROKEAHA.111.000662.

7. Mracsko E, Veltkamp R. Neuroinflammation after intracerebral hemorrhage. Front Cell Neurosci. 2014;8:388. https://doi.org/10. 3389/fncel.2014.00388.
8. Shao Z, Tu S, Shao A. Pathophysiological mechanisms and potential therapeutic targets in intracerebral hemorrhage. Front Pharmacol. 2019;10:1079. https://doi.org/10.3389/fphar.2019. 01079.

9. Chen S, Yang Q, Chen G, Zhang JH. An update on inflammation in the acute phase of intracerebral hemorrhage. Transl Stroke Res. 2015;6(1):4-8. https://doi.org/10.1007/s12975-014-0384-4.

10. Sturgeon JD, Folsom AR, Longstreth WT Jr, Shahar E, Rosamond WD, Cushman M. Risk factors for intracerebral hemorrhage in a pooled prospective study. Stroke. 2007;38(10):2718-25. https:// doi.org/10.1161/STROKEAHA.107.487090.

11. Rost NS, Greenberg SM, Rosand J. The genetic architecture of intracerebral hemorrhage. Stroke. 2008;39(7):2166-73. https:// doi.org/10.1161/STROKEAHA.107.501650.

12. Cervera A, Amaro S, Chamorro A. Oral anticoagulant-associated intracerebral hemorrhage. J Neurol. 2012;259(2):212-24. https:// doi.org/10.1007/s00415-011-6153-3.

13. O'Donnell MJ, Xavier D, Liu L, Zhang H, Chin SL, Rao-Melacini $\mathrm{P}$, et al. Risk factors for ischaemic and intracerebral haemorrhagic stroke in 22 countries (the INTERSTROKE study): a case-control study. Lancet. 2010;376(9735):112-23. https://doi.org/10.1016/ S0140-6736(10)60834-3.

14. Block F, Dafotakis M. Cerebral amyloid angiopathy in stroke medicine. Dtsch Arztebl Int. 2017;114(3):37-42. https://doi.org/ 10.3238/arztebl.2017.0037.

15. Morotti A, Goldstein JN. Diagnosis and management of acute intracerebral hemorrhage. Emerg Med Clin North Am. 2016;34(4):883-99. https://doi.org/10.1016/j.emc.2016.06.010.

16. Dastur $\mathrm{CK}, \mathrm{Yu}$ W. Current management of spontaneous intracerebral haemorrhage. Stroke Vasc Neurol. 2017;2(1):21-9. https:// doi.org/10.1136/svn-2016-000047.

17. Steiner T, Al-Shahi Salman R, Beer R, Christensen H, Cordonnier $\mathrm{C}$, Csiba L, et al. European stroke organisation (ESO) guidelines for the management of spontaneous intracerebral hemorrhage. Int J Stroke. 2014;9(7):840-55. https://doi.org/10.1111/ijs.12309.

18. Hemphill JC 3rd, Greenberg SM, Anderson CS, Becker K, Bendok BR, Cushman M, et al. Guidelines for the management of spontaneous intracerebral hemorrhage: a guideline for healthcare professionals from the American Heart Association/ American Stroke Association. Stroke. 2015;46(7):2032-60. https://doi.org/10.1161/STR.0000000000000069.

19. Frantzias J, Sena ES, Macleod MR, Al-Shahi Salman R. Treatment of intracerebral hemorrhage in animal models: metaanalysis. Ann Neurol. 2011;69(2):389-99. https://doi.org/10. 1002/ana.22243.

20. Selim M, Hanley D, Broderick J, Goldstein JN, Gregson BA, Falcione $\mathrm{G}$, et al. Basic and translational research in intracerebral hemorrhage limitations, priorities, and recommendations. Stroke. 2018;49(5):1308-14. https://doi.org/10.1161/Strokeaha.117. 019539.

21. Lin S, Yin Q, Zhong Q, Lv FL, Zhou Y, Li JQ, et al. Heme activates TLR4-mediated inflammatory injury via MyD88/TRIF signaling pathway in intracerebral hemorrhage. J Neuroinflammation. 2012;9:46. https://doi.org/10.1186/17422094-9-46.

22. Shen X, Ma L, Dong W, Wu Q, Gao Y, Luo C, et al. Autophagy regulates intracerebral hemorrhage induced neural damage via apoptosis and NF-kappaB pathway. Neurochem Int. 2016;96:100 12. https://doi.org/10.1016/j.neuint.2016.03.004.

23. Shen H, Liu C, Zhang D, Yao X, Zhang K, Li H, et al. Role for RIP1 in mediating necroptosis in experimental intracerebral hemorrhage model both in vivo and in vitro. Cell Death Dis. 2017;8(3):e2641. https://doi.org/10.1038/cddis.2017.58.

24. Zille M, Karuppagounder SS, Chen Y, Gough PJ, Bertin J, Finger $\mathrm{J}$, et al. Neuronal death after hemorrhagic stroke in vitro and in vivo shares features of ferroptosis and necroptosis. Stroke. 
2017;48(4):1033-43. https://doi.org/10.1161/STROKEAHA. 116.015609 .

25. Karuppagounder SS, Alin L, Chen Y, Brand D, Bourassa MW, Dietrich K, et al. N-acetylcysteine targets 5 lipoxygenase-derived, toxic lipids and can synergize with prostaglandin E2 to inhibit ferroptosis and improve outcomes following hemorrhagic stroke in mice. Ann Neurol. 2018;84(6):854-72. https://doi.org/10.1002/ ana. 25356.

26. Luo Q, Li D, Bao B, Wan X, Pan B, Tu J, et al. NEMO-binding domain peptides alleviate perihematomal inflammation injury after experimental intracerebral hemorrhage. Neuroscience. 2019;409:43-57. https://doi.org/10.1016/j.neuroscience.2019.04. 041.

27. Hu L, Zhang H, Wang B, Ao Q, Shi J, He Z. MicroRNA-23b alleviates neuroinflammation and brain injury in intracerebral hemorrhage by targeting inositol polyphosphate multikinase. Int Immunopharmacol. 2019;76:105887. https://doi.org/10.1016/j. intimp.2019.105887.

28. Xi ZY, Hu XB, Chen X, Yang Y, Ren J, Wang BF, et al. Protocatechuic acid exerts protective effects via suppression of the P38/JNK- NF-kappa B signalling pathway in an experimental mouse model of intracerebral haemorrhage. Eur J Pharmacol. 2019;854:128-38. https://doi.org/10.1016/j.ejphar.2019.03.008.

29. Sayeed MSB, Alhadidi Q, Shah ZA. Cofilin signaling in hemininduced microglial activation and inflammation. J Neuroimmunol. 2017;313:46-55. https://doi.org/10.1016/j.jneuroim.2017.10.007.

30. Taylor RA, Chang CF, Goods BA, Hammond MD, Mac Grory B, Ai Y, et al. TGF-betal modulates microglial phenotype and promotes recovery after intracerebral hemorrhage. J Clin Invest. 2017;127(1):280-92. https://doi.org/10.1172/JCI88647.

31. Jaremko KM, Chen-Roetling J, Chen L, Regan RF. Accelerated hemolysis and neurotoxicity in neuron-glia-blood clot co-cultures. J Neurochem. 2010;114(4):1063-73. https://doi.org/10.1111/j. 1471-4159.2010.06826.x.

32. Mohan S, Glushakov AV, Decurnou A, Narumiya S, Dore S. Contribution of PGE2 EP1 receptor in hemin-induced neurotoxicity. Front Mol Neurosci. 2013;6:31. https://doi.org/10.3389/ fnmol.2013.00031.

33. Mohan S, Narumiya S, Dore S. Neuroprotective role of prostaglandin PGE2 EP2 receptor in hemin-mediated toxicity. Neurotoxicology. 2015;46:53-9. https://doi.org/10.1016/j.neuro. 2014.10.012.

34. Goldstein L, Teng ZP, Zeserson E, Patel M, Regan RF. Hemin induces an iron-dependent, oxidative injury to human neuron-like cells. J Neurosci Res. 2003;73(1):113-21. https://doi.org/10.1002/ jnr.10633.

35. Lyden PD, JacksonFriedman C, LonzoDoktor L. Medical therapy for intracerebral hematoma with the gamma-aminobutyric acid-A agonist muscimol. Stroke. 1997;28(2):387-91. https://doi.org/10. 1161/01.Str.28.2.387.

36. Yu Z, Chen LF, Li XF, Zhang DP, Chen YM, Wu WF, et al. A double-injection model of intracerebral hemorrhage in rabbits. $\mathrm{J}$ Clin Neurosci. 2009;16(4):545-8. https://doi.org/10.1016/j.jocn. 2008.04.026.

37. Wang LK, Wu GF, Sheng F, Wang F, Feng AR. Minimally invasive procedures reduce perihematomal endothelin-1 levels and the permeability of the BBB in a rabbit model of intracerebral hematoma. Neurol Sci. 2013;34(1):41-9. https://doi.org/10.1007/ s10072-012-0962-8.

38. Gruter BE, Croci D, Schopf S, Nevzati E, d'Allonzo D, Lattmann $\mathrm{J}$, et al. Systematic review and meta-analysis of methodological quality in in vivo animal studies of subarachnoid hemorrhage. Transl Stroke Res. 2020. https://doi.org/10.1007/s12975-02000801-4.
39. Ropper AH, Zervas NT. Cerebral blood flow after experimental basal ganglia hemorrhage. Ann Neurol. 1982;11(3):266-71. https://doi.org/10.1002/ana.410110306.

40. Bullock R, Mendelow AD, Teasdale GM, Graham DI. Intracranial haemorrhage induced at arterial pressure in the rat. Part 1: description of technique, ICP changes and neuropathological findings. Neurol Res. 1984;6(4):184-8. https://doi.org/10.1080/01616412. 1984.11739687.

41. Deinsberger W, Vogel J, Kuschinsky W, Auer LM, Boker DK. Experimental intracerebral hemorrhage: description of a double injection model in rats. Neurol Res. 1996;18(5):475-7. https:// doi.org/10.1080/01616412.1996.11740456.

42. Rynkowski MA, Kim GH, Komotar RJ, Otten ML, Ducruet AF, Zacharia BE, et al. A mouse model of intracerebral hemorrhage using autologous blood infusion. Nat Protoc. 2008;3(1):122-8. https://doi.org/10.1038/nprot.2007.513.

43. Wang J, Fields J, Dore S. The development of an improved preclinical mouse model of intracerebral hemorrhage using double infusion of autologous whole blood. Brain Res. 2008;1222:214 21. https://doi.org/10.1016/j.brainres.2008.05.058.

44. Nakamura T, Xi G, Hua Y, Schallert T, Hoff JT, Keep RF. Intracerebral hemorrhage in mice: model characterization and application for genetically modified mice. J Cereb Blood Flow Metab. 2004;24(5):487-94. https://doi.org/10.1097/00004647200405000-00002.

45. MacLellan CL, Silasi G, Poon CC, Edmundson CL, Buist R, Peeling J, et al. Intracerebral hemorrhage models in rat: comparing collagenase to blood infusion. J Cereb Blood Flow Metab. 2008;28(3):516-25. https://doi.org/10.1038/sj.jcbfm.9600548.

46. Lei B, Sheng H, Wang H, Lascola CD, Warner DS, Laskowitz DT, et al. Intrastriatal injection of autologous blood or clostridial collagenase as murine models of intracerebral hemorrhage. J Vis Exp. 2014;89. https://doi.org/10.3791/51439.

47. Rosenberg GA, Mun-Bryce S, Wesley M, Kornfeld M. Collagenase-induced intracerebral hemorrhage in rats. Stroke. 1990;21(5):801-7. https://doi.org/10.1161/01.str.21.5.801.

48. Aguilar MI, Brott TG. Update in intracerebral hemorrhage. Neurohospitalist. 2011;1(3):148-59. https://doi.org/10.1177/ 1941875211409050.

49. Zhu W, Gao Y, Wan J, Lan X, Han X, Zhu S, et al. Changes in motor function, cognition, and emotion-related behavior after right hemispheric intracerebral hemorrhage in various brain regions of mouse. Brain Behav Immun. 2018;69:568-81. https://doi.org/10. 1016/j.bbi.2018.02.004.

50. Participants NIW. Priorities for clinical research in intracerebral hemorrhage: report from a National Institute of Neurological Disorders and Stroke workshop. Stroke. 2005;36(3):e23-41. https://doi.org/10.1161/01.STR.0000155685.77775.4c.

51. Wang J. Preclinical and clinical research on inflammation after intracerebral hemorrhage. Prog Neurobiol. 2010;92(4):463-77. https://doi.org/10.1016/j.pneurobio.2010.08.001.

52. Chu K, Jeong SW, Jung KH, Han SY, Lee ST, Kim M, et al. Celecoxib induces functional recovery after intracerebral hemorrhage with reduction of brain edema and perihematomal cell death. J Cerebr Blood F Met. 2004;24(8):926-33. https://doi.org/ 10.1097/01.Wcb.0000130866.25040.7d.

53. Xue M, Del Bigio MR. Comparison of brain cell death and inflammatory reaction in three models of intracerebral hemorrhage in adult rats. J Stroke Cerebrovasc Dis. 2003;12(3):152-9. https:// doi.org/10.1016/S1052-3057(03)00036-3.

54. Zhou Y, Wang Y, Wang J, Anne Stetler R, Yang QW. Inflammation in intracerebral hemorrhage: from mechanisms to clinical translation. Prog Neurobiol. 2014;115:25-44. https://doi. org/10.1016/j.pneurobio.2013.11.003.

55. Barratt HE, Lanman TA, Carmichael ST. Mouse intracerebral hemorrhage models produce different degrees of initial and 
delayed damage, axonal sprouting, and recovery. J Cereb Blood Flow Metab. 2014;34(9):1463-71. https://doi.org/10.1038/jcbfm. 2014.107

56. Leclerc JL, Lampert AS, Diller MA, Dore S. PGE2-EP3 signaling exacerbates intracerebral hemorrhage outcomes in 24-mo-old mice. Am J Physiol Heart Circ Physiol. 2016;310(11):H172534. https://doi.org/10.1152/ajpheart.00638.2015.

57. Liew HK, Cheng HY, Huang LC, Li KW, Peng HF, Yang HI, et al. Acute alcohol intoxication aggravates brain injury caused by intracerebral hemorrhage in rats. J Stroke Cerebrovasc Dis. 2016;25(1):15-25. https://doi.org/10.1016/j.jstrokecerebrovasdis. 2015.08.027.

58. Huang LC, Liew HK, Cheng HY, Kuo JS, Hsu WL, Pang CY. Brain magnetic resonance imaging of intracerebral hemorrhagic rats after alcohol consumption. J Stroke Cerebrovasc Dis. 2018;27(12):3493-502. https://doi.org/10.1016/j. jstrokecerebrovasdis.2018.08.022.

59. Chiu CD, Chiu YP, Lin CL, Ji HR, Shen CC, Lee HT, et al. Acetazolamide alleviates sequelae of hyperglycaemic intracerebral haemorrhage by suppressing astrocytic reactive oxygen species. Free Radic Res. 2018;52(9):1010-9. https://doi.org/10.1080/ 10715762.2018.1508838.

60. Cao S, Hua Y, Keep RF, Chaudhary N, Xi G. Minocycline effects on intracerebral hemorrhage-induced iron overload in aged rats: brain iron quantification with magnetic resonance imaging. Stroke. 2018;49(4):995-1002. https://doi.org/10.1161/ STROKEAHA.117.019860.

61. Leclerc JL, Li C, Jean S, Lampert AS, Amador CL, Diller MA, et al. Temporal and age-dependent effects of haptoglobin deletion on intracerebral hemorrhage-induced brain damage and neurobehavioral outcomes. Exp Neurol. 2019;317:22-33. https://doi.org/ 10.1016/j.expneurol.2019.01.011.

62. Anqi X, Ruiqi C, Yanming R, Chao Y. Neuroprotective potential of GDF11 in experimental intracerebral hemorrhage in elderly rats. J Clin Neurosci. 2019;63:182-8. https://doi.org/10.1016/j. jocn.2019.02.016.

63. Tao C, Keep RF, Xi G, Hua Y. CD47 blocking antibody accelerates hematoma clearance after intracerebral hemorrhage in aged rats. Transl Stroke Res. 2019;11:541-51. https://doi.org/10.1007/ s12975-019-00745-4.

64. Ogata J, Fujishima M, Tamaki K, Nakatomi Y, Ishitsuka T, Omae T. Stroke-prone spontaneously hypertensive rats as an experimental model of malignant hypertension. A pathological study. Virchows Arch A Pathol Anat Histol. 1982;394(3):185-94. https://doi.org/10.1007/BF00430664.

65. Lida S, Baumbach GL, Lavoie JL, Faraci FM, Sigmund CD, Heistad DD. Spontaneous stroke in a genetic model of hypertension in mice. Stroke. 2005;36:1253-8.

66. Smeda JS. Hemorrhagic stroke development in spontaneously hypertensive rats fed a North American, Japanese-style diet. Stroke. 1989;20(9):1212-8. https://doi.org/10.1161/01.str.20.9.1212.

67. Ahmad S. Angiotensin receptor antagonists delay nitric oxidedeficient stroke in stroke-prone rats. Eur J Pharmacol. 1997;333(1):39-45. https://doi.org/10.1016/s0014-2999(97) 01089-3.

68. Wakisaka Y, Chu Y, Miller JD, Rosenberg GA, Heistad DD. Spontaneous intracerebral hemorrhage during acute and chronic hypertension in mice. J Cereb Blood Flow Metab. 2010;30(1):5669. https://doi.org/10.1038/jcbfm.2009.183.

69. Wakisaka Y, Chu Y, Miller JD, Rosenberg GA, Heistad DD. Critical role for copper/zinc-superoxide dismutase in preventing spontaneous intracerebral hemorrhage during acute and chronic hypertension in mice. Stroke. 2010;41(4):790-7. https://oi.org/ 10.1161/STROKEAHA.109.569616.

70. Li H, Xu H, Wen H, Liu T, Sun Y, Xiao N, et al. Overexpression of LH3 reduces the incidence of hypertensive intracerebral hemorrhage in mice. J Cereb Blood Flow Metab. 2019;39(3): 547-61. https://doi.org/10.1177/0271678X18815791.

71. Chen B, Sun H, Zhao Y, Lun P, Feng Y. An 85-gene coexpression module for progression of hypertension-induced spontaneous intracerebral hemorrhage. DNA Cell Biol. 2019;38(5):449-56. https://doi.org/10.1089/dna.2018.4425.

72. Winkler DT, Bondolfi L, Herzig MC, Jann L, Calhoun ME, Wiederhold $\mathrm{KH}$, et al. Spontaneous hemorrhagic stroke in a mouse model of cerebral amyloid angiopathy. J Neurosci. 2001;21(5):1619-27.

73. Herzig MC, Winkler DT, Burgermeister P, Pfeifer M, Kohler E, Schmidt SD, et al. Abeta is targeted to the vasculature in a mouse model of hereditary cerebral hemorrhage with amyloidosis. Nat Neurosci. 2004;7(9):954-60. https://doi.org/10.1038/nn1302.

74. Davis J, Xu F, Deane R, Romanov G, Previti ML, Zeigler K, et al. Early-onset and robust cerebral microvascular accumulation of amyloid beta-protein in transgenic mice expressing low levels of a vasculotropic Dutch/Iowa mutant form of amyloid beta-protein precursor. J Biol Chem. 2004;279(19):20296-306. https://doi.org/ 10.1074/jbc.M312946200.

75. Fisher M, Vasilevko V, Passos GF, Ventura C, Quiring D, Cribbs $\mathrm{DH}$. Therapeutic modulation of cerebral microhemorrhage in a mouse model of cerebral amyloid angiopathy. Stroke. 2011;42(11):3300-3. https://doi.org/10.1161/STROKEAHA. 111.626655 .

76. Passos GF, Kilday K, Gillen DL, Cribbs DH, Vasilevko V. Experimental hypertension increases spontaneous intracerebral hemorrhages in a mouse model of cerebral amyloidosis. J Cereb Blood Flow Metab. 2016;36(2):399-404. https://doi.org/10.1177/ $0271678 X 15606720$.

77. Van Agtmael T, Bailey MA, Schlotzer-Schrehardt U, Craigie E, Jackson IJ, Brownstein DG, et al. Col4al mutation in mice causes defects in vascular function and low blood pressure associated with reduced red blood cell volume. Hum Mol Genet. 2010;19(6):1119-28. https://doi.org/10.1093/hmg/ddp584.

78. Jeanne M, Jorgensen J, Gould DB. Molecular and genetic analyses of collagen type IV mutant mouse models of spontaneous intracerebral hemorrhage identify mechanisms for stroke prevention. Circulation. 2015;131(18):1555-U64. https://doi.org/10.1161/ Circulationaha.114.013395.

79. Ratelade J, Klug NR, Lombardi D, Angelim M, Dabertrand F, Domenga-Denier $\mathrm{V}$, et al. Reducing hypermuscularization of the transitional segment between arterioles and capillaries protects against spontaneous intracerebral hemorrhage. Circulation. 2020;141:2078-94. https://doi.org/10.1161/CIRCULATIONAHA. 119.040963.

80. Knight RA, Han YX, Nagaraja TN, Whitton P, Ding J, Chopp M, et al. Temporal MRI assessment of intracerebral hemorrhage in rats. Stroke. 2008;39(9):2596-602. https://doi.org/10.1161/ Strokeaha.107.506683.

81. Matsushita H, Hijioka M, Hisatsune A, Isohama Y, Iwamoto S, Terasawa $\mathrm{H}$, et al. MRI-based analysis of intracerebral hemorrhage in mice reveals relationship between hematoma expansion and the severity of symptoms. PLoS One. 2013;8(7). https://doi. org/10.1371/journal.pone.0067691.

82. Jing C, Bian L, Wang M, Keep RF, Xi G, Hua Y. Enhancement of hematoma clearance with CD47 blocking antibody in experimental intracerebral hemorrhage. Stroke. 2019;50(6):1539-47. https:// doi.org/10.1161/STROKEAHA.118.024578.

83. Shi E, Shi K, Qiu S, Sheth KN, Lawton MT, Ducruet AF. Chronic inflammation, cognitive impairment, and distal brain region alteration following intracerebral hemorrhage. FASEB J. 2019;33(8): 9616-26. https://doi.org/10.1096/fj.201900257R.

84. Liu C, Xie B, Li M, Yang GY, Tong S. Spatiotemporal changes of cerebral blood flow following hemorrhagic stroke by laser speckle 
imaging. Conf Proc IEEE Eng Med Biol Soc. 2011;2011:6150-3. https://doi.org/10.1109/IEMBS.2011.6091519.

85. Lieschke GJ, Currie PD. Animal models of human disease: zebrafish swim into view. Nat Rev Genet. 2007;8(5):353-67. https://doi.org/10.1038/nrg2091.

86. Howe K, Clark MD, Torroja CF, Torrance J, Berthelot C, Muffato $\mathrm{M}$, et al. The zebrafish reference genome sequence and its relationship to the human genome. Nature. 2013;496(7446):498-503. https://doi.org/10.1038/nature12111.

87. Crilly S, Njegic A, Laurie SE, Fotiou E, Hudson G, Barrington J, et al. Using zebrafish larval models to study brain injury, locomotor and neuroinflammatory outcomes following intracerebral haemorrhage. F1000Res. 2018;7:1617. https://oi.org/10.12688/ f1000research.16473.2.

88. Crilly S, Njegic A, Parry-Jones AR, Allan SM, Kasher PR. Using zebrafish larvae to study the pathological consequences of hemorrhagic stroke. Jove-J Vis Exp. 2019;(148). https://doi.org/10. 3791/59716.

89. Wang Y, Pan L, Moens CB, Appel B. Notch3 establishes brain vascular integrity by regulating pericyte number. Development. 2014;141(2):307-17. https://doi.org/10.1242/dev.096107.

90. Liu J, Fraser SD, Faloon PW, Rollins EL, Vom Berg J, StarovicSubota $\mathrm{O}$, et al. A betaPix Pak2a signaling pathway regulates cerebral vascular stability in zebrafish. Proc Natl Acad Sci U S A. 2007;104(35):13990-5. https://doi.org/10.1073/pnas. 0700825104.

91. Buchner DA, Su F, Yamaoka JS, Kamei M, Shavit JA, Barthel LK, et al. pak2a mutations cause cerebral hemorrhage in redhead zebrafish. Proc Natl Acad Sci U S A. 2007;104(35):13996-4001. https://doi.org/10.1073/pnas.0700947104.

92. Eisa-Beygi S, Benslimane FM, El-Rass S, Prabhudesai S, Abdelrasoul MKA, Simpson PM, et al. Characterization of endothelial cilia distribution during cerebral-vascular development in zebrafish ( Danio rerio). Arterioscler Thromb Vasc Biol. 2018;38(12):2806-18. https://doi.org/10.1161/ATVBAHA.118. 311231.

93. Gjini E, Hekking LH, Kuchler A, Saharinen P, Wienholds E, Post JA, et al. Zebrafish Tie-2 shares a redundant role with Tie-1 in heart development and regulates vessel integrity. Dis Model Mech. 2011;4(1):57-66. https://doi.org/10.1242/dmm.005033.

94. Eisa-Beygi S, Hatch G, Noble S, Ekker M, Moon TW. The 3hydroxy-3-methylglutaryl-CoA reductase (HMGCR) pathway regulates developmental cerebral-vascular stability via prenylation-dependent signalling pathway. Dev Biol. 2013;373(2):258-66. https://doi.org/10.1016/j.ydbio.2012.11. 024 .

95. Wang X, Dong Y, Qi X, Huang C, Hou L. Cholesterol levels and risk of hemorrhagic stroke: a systematic review and meta-analysis. Stroke. 2013;44(7):1833-9. https://doi.org/10.1161/ STROKEAHA.113.001326.

96. Wieberdink RG, Poels MM, Vernooij MW, Koudstaal PJ, Hofman A, van der Lugt A, et al. Serum lipid levels and the risk of intracerebral hemorrhage: the Rotterdam Study. Arterioscler Thromb Vasc Biol. 2011;31(12):2982-9. https://doi.org/10. 1161/ATVBAHA.111.234948.

97. Phuah CL, Raffeld MR, Ayres AM, Viswanathan A, Greenberg SM, Biffi A, et al. Subacute decline in serum lipids precedes the occurrence of primary intracerebral hemorrhage. Neurology. 2016;86(22):2034-41. https://doi.org/10.1212/WNL. 0000000000002716 .

98. Chang JJ, Katsanos AH, Khorchid Y, Dillard K, Kerro A, Burgess LG, et al. Higher low-density lipoprotein cholesterol levels are associated with decreased mortality in patients with intracerebral hemorrhage. Atherosclerosis. 2018;269:14-20. https://doi.org/10. 1016/j.atherosclerosis.2017.12.008.
99. Sun L, Clarke R, Bennett D, Guo Y, Walters RG, Hill M, et al. Causal associations of blood lipids with risk of ischemic stroke and intracerebral hemorrhage in Chinese adults. Nat Med. 2019;25(4):569-74. https://doi.org/10.1038/s41591-019-0366-x.

100. Campos LM, Rios EA, Guapyassu L, Midlej V, Atella GC, Herculano-Houzel S, et al. Alterations in zebrafish development induced by simvastatin: comprehensive morphological and physiological study, focusing on muscle. Exp Biol Med (Maywood). 2016;241(17):1950-60. https://doi.org/10.1177/ 1535370216659944.

101. Rice GI, Bond J, Asipu A, Brunette RL, Manfield IW, Carr IM, et al. Mutations involved in Aicardi-Goutieres syndrome implicate SAMHD1 as regulator of the innate immune response. Nat Genet. 2009;41(7):829-32. https://doi.org/10.1038/ng.373.

102. Ramesh V, Bernardi B, Stafa A, Garone C, Franzoni E, Abinun M, et al. Intracerebral large artery disease in Aicardi-Goutieres syndrome implicates SAMHD1 in vascular homeostasis. Dev Med Child Neurol. 2010;52(8):725-32. https://doi.org/10.1111/j. 1469-8749.2010.03727.x.

103. Thiele H, du Moulin M, Barczyk K, George C, Schwindt W, Nurnberg G, et al. Cerebral arterial stenoses and stroke: novel features of Aicardi-Goutieres syndrome caused by the Arg164X mutation in SAMHD1 are associated with altered cytokine expression. Hum Mutat. 2010;31(11):E1836-50. https://doi.org/10. 1002/humu.21357.

104. Xin B, Jones S, Puffenberger EG, Hinze C, Bright A, Tan H, et al. Homozygous mutation in SAMHD1 gene causes cerebral vasculopathy and early onset stroke. Proc Natl Acad Sci U S A. 2011;108(13):5372-7. https://doi.org/10.1073/pnas.1014265108.

105. du Moulin M, Nurnberg P, Crow YJ, Rutsch F. Cerebral vasculopathy is a common feature in Aicardi-Goutieres syndrome associated with SAMHD1 mutations. Proc Natl Acad Sci U S A. 2011;108(26):E232-author reply E3. https://doi.org/10.1073/ pnas. 1104699108 .

106. Behrendt R, Schumann T, Gerbaulet A, Nguyen LA, Schubert N, Alexopoulou D, et al. Mouse SAMHD1 has antiretroviral activity and suppresses a spontaneous cell-intrinsic antiviral response. Cell Rep. 2013;4(4):689-96. https://doi.org/10.1016/j.celrep.2013.07. 037.

107. Rehwinkel J, Maelfait J, Bridgeman A, Rigby R, Hayward B, Liberatore RA, et al. SAMHD1-dependent retroviral control and escape in mice. EMBO J. 2013;32(18):2454-62. https://doi.org/ 10.1038/emboj.2013.163.

108. Kasher PR, Jenkinson EM, Briolat V, Gent D, Morrissey C, Zeef LA, et al. Characterization of samhd 1 morphant zebrafish recapitulates features of the human type I interferonopathy AicardiGoutieres syndrome. J Immunol. 2015;194(6):2819-25. https:// doi.org/10.4049/jimmunol.1403157.

109. Zhou Q, Yang D, Ombrello AK, Zavialov AV, Toro C, Zavialov $\mathrm{AV}$, et al. Early-onset stroke and vasculopathy associated with mutations in ADA2. N Engl J Med. 2014;370(10):911-20. https://doi.org/10.1056/NEJMoa1307361.

110. Walcott BP, Peterson RT. Zebrafish models of cerebrovascular disease. J Cereb Blood Flow Metab. 2014;34(4):571-7. https:// doi.org/10.1038/jcbfm.2014.27.

111. Ma Q, Khatibi NH, Chen H, Tang J, Zhang JH. History of preclinical models of intracerebral hemorrhage. Acta Neurochir Suppl. 2011;111:3-8. https://doi.org/10.1007/978-3-7091-06938 -1.

112. Lin XT, Tang YC, Sun B, Hou ZY, Meng HW, Li ZP, et al. Cerebral glucose metabolism: influence on perihematomal edema formation after intracerebral hemorrhage in cat models. Acta Radiol. 2010;51(5):549-54. https://doi.org/10.3109/ 02841851003660065 .

113. Boltze J, Ferrara F, Hainsworth AH, Bridges LR, Zille M, Lobsien D, et al. Lesional and perilesional tissue characterization by automated 
image processing in a novel gyrencephalic animal model of peracute intracerebral hemorrhage. J Cereb Blood Flow Metab. 2019;39(12): 2521-35. https://doi.org/10.1177/0271678X18802119.

114. Mendelow AD, Gregson BA, Fernandes HM, Murray GD, Teasdale GM, Hope DT, et al. Early surgery versus initial conservative treatment in patients with spontaneous supratentorial intracerebral haematomas in the International Surgical Trial in Intracerebral Haemorrhage (STICH): a randomised trial. Lancet. 2005;365(9457): 387-97. https://doi.org/10.1016/S0140-6736(05)17826-X.

115. Mendelow AD, Gregson BA, Rowan EN, Murray GD, Gholkar A, Mitchell PM, et al. Early surgery versus initial conservative treatment in patients with spontaneous supratentorial lobar intracerebral haematomas (STICH II): a randomised trial. Lancet. 2013;382(9890):397-408. https://doi.org/10.1016/S01406736(13)60986-1.

116. Morgan T, Zuccarello M, Narayan R, Keyl P, Lane K, Hanley D. Preliminary findings of the minimally-invasive surgery plus rtPA for intracerebral hemorrhage evacuation (MISTIE) clinical trial. Acta Neurochir Suppl. 2008;105:147-51. https://doi.org/10. 1007/978-3-211-09469-3 30.

117. Mould WA, Carhuapoma JR, Muschelli J, Lane K, Morgan TC, McBee NA, et al. Minimally invasive surgery plus recombinant tissue-type plasminogen activator for intracerebral hemorrhage evacuation decreases perihematomal edema. Stroke. 2013;44(3): 627-34. https://doi.org/10.1161/STROKEAHA.111.000411.

118. Hanley DF, Thompson RE, Rosenblum M, Yenokyan G, Lane K, McBee N, et al. Efficacy and safety of minimally invasive surgery with thrombolysis in intracerebral haemorrhage evacuation (MISTIE III): a randomised, controlled, open-label, blinded endpoint phase 3 trial. Lancet. 2019;393(10175):1021-32. https://doi. org/10.1016/S0140-6736(19)30195-3.

119. Liu XC, Jing LY, Yang MF, Wang K, Wang Y, Fu XY, et al. Enhanced neuroprotection of minimally invasive surgery joint local cooling lavage against ICH-induced inflammation injury and apoptosis in rats. Cell Mol Neurobiol. 2016;36(5):647-55. https:// doi.org/10.1007/s10571-015-0245-Z.

120. Pei HT, Jiang T, Liu GF, Li ZX, Luo K, An JJ, et al. The effect of minimally invasive hematoma aspiration on the JNK signal transduction pathway after experimental intracerebral hemorrhage in rats. Int $\mathrm{J}$ Mol Sci. 2016;17(5). https://doi.org/10.3390/ijms17050710.

121. Lei B, Wang H, Jeong S, Hsieh JT, Majeed M, Dawson H, et al. Progesterone improves neurobehavioral outcome in models of intracerebral hemorrhage. Neuroendocrinology. 2016;103(6):66577. https://doi.org/10.1159/000442204.

122. Hsieh JT, Lei B, Sheng H, Venkatraman T, Lascola CD, Warner DS, et al. Sex-specific effects of progesterone on early outcome of intracerebral hemorrhage. Neuroendocrinology. 2016;103(5): 518-30. https://doi.org/10.1159/000440883.

123. Xie Q, Xi G, Keep RF, Hua Y. Effects of gender and estrogen receptors on iron-induced brain edema formation. Acta Neurochir Suppl. 2016;121:341-5. https://doi.org/10.1007/978-3-319-18497-5_59.

124. Chen-Roetling J, Kamalapathy P, Cao Y, Song W, Schipper HM, Regan RF. Astrocyte heme oxygenase-1 reduces mortality and improves outcome after collagenase-induced intracerebral hemorrhage. Neurobiol Dis. 2017;102:140-6. https://doi.org/10.1016/j. nbd.2017.03.008.

125. Dai S, Hua Y, Keep RF, Novakovic N, Fei Z, Xi G. Minocycline attenuates brain injury and iron overload after intracerebral hemorrhage in aged female rats. Neurobiol Dis. 2019;126:76-84. https://doi.org/10.1016/j.nbd.2018.06.001.

126. Wagner KR, Xi G, Hua Y, Kleinholz M, de Courten-Myers GM, Myers RE, et al. Lobar intracerebral hemorrhage model in pigs: rapid edema development in perihematomal white matter. Stroke. 1996;27(3):490-7. https://doi.org/10.1161/01.str.27.3.490.
127. Xi G, Wagner KR, Keep RF, Hua Y, de Courten-Myers GM, Broderick JP, et al. Role of blood clot formation on early edema development after experimental intracerebral hemorrhage. Stroke. 1998;29(12):2580-6. https://doi.org/10.1161/01.str.29.12.2580.

128. Wagner KR. Modeling intracerebral hemorrhage: glutamate, nuclear factor-kappa B signaling and cytokines. Stroke. 2007;38(2 Suppl): 753-8. https://doi.org/10.1161/01.STR.0000255033.02904.db.

129. Gu Y, Hua Y, Keep RF, Morgenstern LB, Xi G. Deferoxamine reduces intracerebral hematoma-induced iron accumulation and neuronal death in piglets. Stroke. 2009;40(6):2241-3. https://doi. org/10.1161/STROKEAHA.108.539536.

130. Selim M, Foster LD, Moy CS, Xi G, Hill MD, Morgenstern LB, et al. Deferoxamine mesylate in patients with intracerebral haemorrhage (i-DEF): a multicentre, randomised, placebo-controlled, double-blind phase 2 trial. Lancet Neurol. 2019;18(5):428-38. https://doi.org/10.1016/S1474-4422(19)30069-9.

131. Wagner KR, Xi G, Hua Y, Zuccarello M, de Courten-Myers GM, Broderick JP, et al. Ultra-early clot aspiration after lysis with tissue plasminogen activator in a porcine model of intracerebral hemorrhage: edema reduction and blood-brain barrier protection. J Neurosurg. 1999;90(3):491-8. https://doi.org/10.3171/jns.1999.90.3.0491.

132. Mun-Bryce S, Wilkerson AC, Papuashvili N, Okada YC. Recurring episodes of spreading depression are spontaneously elicited by an intracerebral hemorrhage in the swine. Brain Res. 2001;888(2):248 55. https://doi.org/10.1016/s0006-8993(00)03068-7.

133. Shi SX, Li YJ, Shi K, Wood K, Ducruet AF, Liu Q. IL (Interleukin)15 bridges astrocyte-microglia crosstalk and exacerbates brain injury following intracerebral hemorrhage. Stroke. 2020;51(3):967-74. https://doi.org/10.1161/STROKEAHA.119.028638.

134. Li M, Ren H, Sheth KN, Shi FD, Liu Q. A TSPO ligand attenuates brain injury after intracerebral hemorrhage. FASEB J. 2017;31(8): 3278-87. https://doi.org/10.1096/fj.201601377RR.

135. Wu H, Zhang ZY, Hu XL, Zhao RB, Song YJ, Ban XA, et al. Dynamic changes of inflammatory markers in brain after hemorrhagic stroke in humans: a postmortem study. Brain Res. 2010;1342:111-7. https://doi.org/10.1016/j.brainres.2010.04.033.

136. Moursel LG, van Roon-Mom WMC, Kielbasa SM, Mei H, Buermans HPJ, van der Graaf LM, et al. Brain transcriptomic analysis of hereditary cerebral hemorrhage with amyloidosis-Dutch type. Front Aging Neurosci. 2018;10. https://doi.org/10.3389/fnagi.2018.00102.

137. Stamova B, Ander BP, Jickling G, Hamade F, Durocher M, Zhan X, et al. The intracerebral hemorrhage blood transcriptome in humans differs from the ischemic stroke and vascular risk factor control blood transcriptomes. J Cereb Blood Flow Metab. 2019;39(9):1818-35. https://doi.org/10.1177/0271678X18769513.

138. Meng Z, Zhao T, Zhou K, Zhong Q, Wang Y, Xiong X, et al. A20 Ameliorates Intracerebral Hemorrhage-Induced Inflammatory Injury by Regulating TRAF6 Polyubiquitination. J Immunol. 2017;198(2):820-31. https://doi.org/10.4049/jimmunol.1600334.

139. Zhou K, Cui S, Duan W, Zhang J, Huang J, Wang L, et al. Coldinducible RNA-binding protein contributes to intracerebral hemorrhage-induced brain injury via TLR4 signaling. Brain Behav. 2020:e01618. https://doi.org/10.1002/brb3.1618.

140. Lu X, Zhang HY, He ZY. MicroRNA-181c provides neuroprotection in an intracerebral hemorrhage model. Neural Regen Res. 2020;15(7):1274-82. https://doi.org/10.4103/1673-5374.272612.

141. Del Bigio MR, Deck JH, Davidson GS. Glial swelling with eosinophilia in human post-mortem brains: a change indicative of plasma extravasation. Acta Neuropathol. 2000;100(6):688-94. https:// doi.org/10.1007/s004010000236.

Publisher's Note Springer Nature remains neutral with regard to jurisdictional claims in published maps and institutional affiliations. 